two photographs taken by Dr. Lunt at the Cape Observatory in October of last year, and data for the computation of a provisional orbit were provided by fifteen plates taken later (. Astrophysical Journal, vol. xlvii., p. 134). The magnitude of the star is $5 \cdot 28$, and the spectrum of type $\mathrm{K}$. The semi-amplitude of the velocity curve is $22.75 \mathrm{~km}$. $/ \mathrm{sec}$., and the system is approaching with a velocity of $3.0 \mathrm{~km} . / \mathrm{sec}$. relatively to the sun, or receding at $7.3 \mathrm{~km} . / \mathrm{sec}$. when the component of the solar motion is eliminated. The star is of special interest, inasmuch as the period is only $\times 3.25$ days, whereas Campbell found no spectroscopic binaries of the later types $\mathrm{G}, \mathrm{K}$, and $\mathrm{M}$ having periods less than twenty days.

\section{THE TOTAL SOLAR ECLIPSE OF JUNE 8, I9I8.}

\section{THE "Eclipse Number" of Popular Astronomy} (vol. xxvi., No. 5, May) gives special prominence to a number of articles on the approaching total eclipse of the sun visible in the United States. Prof. H. C. Wilson gives a general account of eclipse phenomena and of the circumstances of the eclipse of June 8, to which is appended a series of letters indicating the plans of leading astronomers for observing the eclipse. The shadow first strikes the earth in the Pacific south of Japan, then passes north-westward, and reaches its highest latitude about 500 miles south of the Alaskan coast in long. $x_{52^{\circ}} \mathrm{W} . ;$ on its landward course it passes from the western coast of Washington by way of Denver to Florida, the duration of totality on the central line gradually diminishing from. I2. to $5^{\circ} \mathrm{sec}$. Quite a large number of American astronomers are too fully occupied with war-work to undertake observations, but several well-equipped parties will occupy stations along the track. Ample provision appears to have been made for direct photographs of the corona on large and small scales, as well as for spectroscopic observations, and some of the observers will make special efforts to obtain photographs suitable for testing the deflection of rays of light from stars near the sun which is predicted by Einstein's theory of relativity. Prof. Hale will be in Wyoming with a party from the Mt. Wilson Observatory, and will attempt to determine the rotation of the corona from displacements of the green coronal line, besides obtaining photographs for studies of the chromospheric spectrum at different levels. Prof. Campbell's programme is somewhat restricted by the delay in the return of the instruments employed by him in Russia in I9I4, but some instruments are available for photographs of the corona and of its spectrum.

The observations proposed by Prof. Abbet include measures of the brightness of the sky and of the outgoing radiation before, during, and after the eclipse. Prof. Stebbins will endeavour to secure photometric measures of the corona by means of potassium and rubidium photo-electric cells. A large party from the U.S. Naval Observatory will be located at Baker, Oregon, and in addition to many other observations, will attempt to extend the spectroscopic observations into the extreme red by the use of plates stained with dicyanin. Profs. Frost and Barnard have also prepared an extensive programme of photographs of the corona and its spectrum at Green River, Wyoming. In a separate article Prof. Frost directs attention to the valuable observations of the chromospheric spectrum which are possible at places within 200 miles of the eclipse track, as indicated by Newall and Fowler in 1912 .

On account of the war, it is not expected that there will be any expeditions from foreign countries to observe this eclipse.

$$
\text { NO. } 2535 \text {, VOL. IOI] }
$$

DIURNAL VARIATION OF ATMOSPHERIC PRESSURE.

THE effect of geographical latitude on the semidiurnal wave of atmospheric pressure is fairly regular and well marked, but the variation of the diurnal wave has attracted less attention since Angot in 1887 , and also Hann, showed conclusively its dependence on secondary local conditions. Three Japanese investigators from the Geophysical Seminary of the Physical Institute, Tokya, contribute an account ${ }^{1}$ of a preliminary attempt to: trace more detinitely the mechanism of these local influences, one of the most abvious of which, under the name of "continentality," has recently been attracting the attention of $\mathrm{Mr}$. C. E. P. Brooks in this country in connection with climate, and with a purely geographical theory, of the Ice age.

The elementary definition of continentaity as the percentage of land in a circle of definite size (say $10^{\circ}$ radius) surrounding the station is clearly insufficient, so much depending upon the orientation and shape of the coast line or lines that the form of the function is bound to be complicated. The Japanese authors soon come to the conclusion that it is not linear, and are constrained to make a series of simplifying assumptions in order to reach a workable hypothesis. The assumptions are no more probable than those of the early days of the theory of tides, with which the present problem has obvious analogies.

With these limitations the authors appear to account for such features as the variation with longitude, the inversion of phase near the poles, and the minimum amplitude near the coast, but a general solution of the problem has evidently not yet been reached. They indicate the lines on which they propose to continue the investigation, and conclude with a representative set of daily variation curves for ten British observatories, showing considerable dissimilarity, those of Oxford and Aberdeen, for instance, being almost the converse of each other. A systematic series of stations within the Empire, chosen with special reference to the elucidation of this problem, may well form part of the programme of co-ordinated British Empire meteorology so strongly advocated by Major Lyons in his presidential address to the Royal Meteorological Society.

The barometric variations dealt with in the above paper, as generally studied, are naturally to be reoarded as vertical oscillations of the free atmosphere, though there is a possible difficulty in the differentiation between statical and dynamical pressure, when an ascending or descending current is in question. But there is also a very decided horizontal oscillation or motion of the free atmosphere, and this has begun to attract attention since the use of pilot balloons has provided more information about the direction of the wind at different heights than can be inferred from the motion of clouds. A paper from Batavia ${ }^{2}$ has appeared in the Proceedings of the Royal Academy of Amsterdam dealing with the semi-diurnal variation of this motion.

There is a good deal of uncertainty about the investigation, even in a favourable place like Batavia, where atmospheric conditions are as a rule very quiet and steady. Observations were made not only at Batavia, but also at a neighbouring mountain station of 3000 metres elevation, as well as from a small coral island, to eliminate the land-effect. Single observations are 1 "On Diurnal Variation of Barometric Pressure." By 'U. Teradas
M. Kiuti, and J. Tukamoto. Journal of the College of Science, Imperial University of Tokyo, vol. xli., art. I (November 20 , r917).

2 "The Semi-diurnal Horizontal Oscillation of the Free Atmosphere up to ro $\mathrm{km}$. above Sea-level Deduced from Pilat-Balloon Observations at Batavia." By W, van Bemmelen and J. Boerema. Proceedings Royal Acad. Amsterdam, vol, xx., pp. r19-35+plate. 